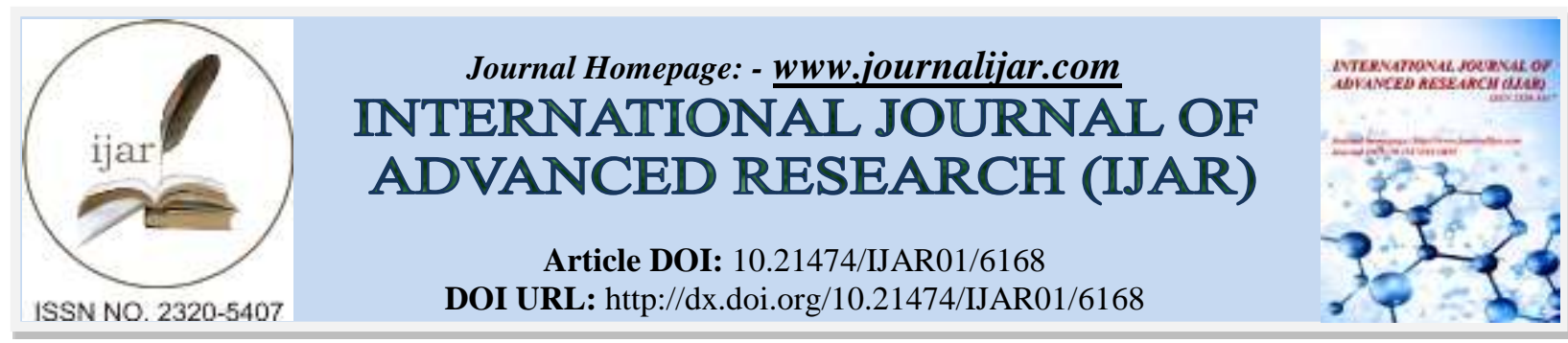

RESEARCH ARTICLE

\title{
CURRENT CLASSIFICATIONS AND PREPARATION TECHNIQUES OF DENTAL CERAMIC LAMINATE VENEERS (REVIEW ARTICLE).
}

\author{
Basem M Abuzenada ${ }^{1}$, Ahmed Saleh Alanazi ${ }^{2}$, Waseem M Al saydali ${ }^{2}$, Ahmed M El-Marakby ${ }^{3,4}$, Hasan A \\ Koshak $^{2}$ and Abdulaziz Ahmed Alharthi'. \\ 1. Assistant professor, King Abdul Aziz University and BMC, Kingdom of Saudi Arabia. \\ 2. Post graduate dentist, Al-farabi College for Dentistry and Nursng, Riyadh, Kingdom of Saudi Arabia. \\ 3. Assistant prof. at Department of Restorative Dental Sciences, Al-Farabi College for Dentistry and Nursng, \\ Riyadh, Kingdom of Saudi Arabia. \\ 4. Lecturer at Department of Operative Dentistry, Faculty of Dentistry, Al-Azhar University, Assiut branch, \\ Egypt.
}

\section{Manuscript Info}

Manuscript History

Received: 25 October 2017

Final Accepted: 27 November 2017

Published: December 2017

Keywords:-

Ceramic Materials, Laminate Veneers,

Minimally Invasive Dentistry, Adhesive Luting.

\begin{abstract}
The continuous progression in the field of ceramics in dentistry lead to a revolution in conservative dental treatment. This is offered the clinicians various solutions for many situations that need esthetic dental improvement. Laminate veneers considered highly functional and esthetically indirect restoratives that treat unaesthetic anterior teeth with minimally invasive preparation. Cases needed for correction of crown length and width, correction of minor malformations of anterior teeth, closure of spacingl diastema, masking some intrinsic discoloration; e.g. Tetracycline stain and treatment of dental fluorosis are examples for solutions varieties that can be achieved when using ceramic laminate veneers. The more improvement in ceramic material, adhesive luting cement and preparation techniques offer many options for clinicians. The Success of clinical veneer cases relays to a great extent on a proper knowledge, and well training of both operator and technician. These can be achieved through more focusing on the recent trends in ceramic materials, preparation techniques and application of adhesive luting cement. The following review article is searching for the current state of the art of dental laminate veneers including veneers material, preparation modalities, and applications techniques.
\end{abstract}

Copy Right, IJAR, 2017,. All rights reserved.

\section{Introduction:-}

Nowadays, patient demands of getting a better esthetic restoration and smile design improvement with minimally invasive tooth preparation can be easily achieved through new adhesive technologies and ultra-thin ceramic veneers techniques. Clinical success of veneers cases depends on right choice of available materials, more conservative preparation techniques and proper adhesive application (1). With the evolvement of ceramic materials and improvement of preparation techniques, ceramic laminate veneers provide the ultimate option for a minimally invasive esthetic approach that enhance the patient smile with less or sometimes none tooth preparation $(2,3)$. Since its introduction a few decades ago, ceramic veneers represented a revolution in restorative and prosthetic dentistry 
$(4,5)$. Currently, wide range varieties of materials and techniques need continuous education and well knowledge for both dentist and dental ceramic technician. Many studies revealed that excellent clinical results of veneer cases could be gained through a well-trained expertise dentist and a highly skilled laboratory dental ceramist $(6,7)$. Due to its long term maintenance of aesthetics, many clinical studies concluded the excellence performance of porcelain laminate veneers and minimum failure rate when compared to other treatment restorative alternatives (8-12) On the other hand, the clinical studies not agreed with the previous opinion clarified the most common causes of veneers failure. These might include improper case selection; e.g. patient with deep bite, abnormal articulation, improper selection of un-erupted teeth, excessive loss of dental and periodontal soft tissues, excessive dentin reduction and improper application of resin luting cement $(13,14)$. But in general, if the meticulous rules of case selection, adequate preparation and proper application of luting agent, the porcelain laminate veneers are considered more durable than direct composite veneering $(7,13)$. The manifestations of veneer failures either mechanically or biologically were concluded in some clinical studies. Loss of esthetics recorded $31 \%$, weak periodontal support $12.5 \%$, lack of veneer desirable mechanical properties $31 \%$, poor luting and improper retention $12.5 \%$, caries recurrence $6 \%$, and fracture of tooth structure recorded 6\%. (15-19)

\section{Classification of dental ceramics:-}

Ceramic laminate veneers represent a part of the classification of ceramics in dentistry. It is apparently an impossible task to make a complete classification of ceramics in dentistry due to continuous compositions improvements. Nevertheless, the following provided a general idea (20).

\section{Classification based on microstructure:-}

Category 1: Glass-based systems (mainly silica), Category 2: Glass-based systems (mainly silica) with fillers usually crystalline (typically leucite or a different high-fusing glass). These can be further classified into (a) Low-tomoderate leucite-containing (less than 45\%) feldspathic glass, (b) High-leucite (more than 50\%)-containing glass. Glass-ceramics are example for this type (eg: IPS Empress), (c) Lithium disilicate glass-ceramics. Examples for this type may include (IPS e-max pressable \& machinable ceramics), Category 3: Crystalline-based systems with glass fillers (most fillers are from alumina) and Category 4: Polycrystalline solids (containing both alumina and zirconia particles)

\section{Classification based on processing technique:-}

Glass-based powder/liquid systems, (2) Pressable blocks of glass-based systems and (3) Computer-aided design / Computer-assessed manufacturing (CAD/CAM) systems

\section{Classification based on type:-}

Feldspathic porcelain, leucite-reinforced porcelain, aluminous porcelain; glass-infiltrated alumina, glass-infiltrated zirconia and glass ceramics.

\section{Classification based on Composition:-}

Silicates: These are characterized by amorphous glass phase, containing predominantly silica.

Oxide ceramics: In dentistry applications; only oxide ceramics are used because of processing difficulty of the nonoxide ceramics. Oxide ceramics contain a principal crystalline phase like Alumina. Zirconia: a very high fracture toughness of zirconia even with a very thin thickness accompanied with highly glazed esthetic appearance are main advantages. Glass ceramics: type of ceramics that contains a glass matrix phase \& at least one crystal phase.

Although classification of dental ceramics based on composition is not much of importance today, due to advances made, it was included for historical importance.

\section{Classification of veneers based on processing techniques:- Feldspathic porcelain veneers:-}

Three types of materials were used for porcelain laminate veneers; porcelain that fired on the refractory dies, the heat pressed glass ceramic and chair-side computer-aided design \ computer-assessed manufacturing (CAD-CAM) system. Feldspathic porcelain veneers considered the least strength among the other types, but still more durable than direct composite veneers (14). Some authors concluded that if the veneer case was properly selected and meticulous clinical procedures are followed during tooth preparation, both feldspathic porcelain and hot-pressed glass-ceramics presented long-term success rates reaching $96 \%-98 \%$ up to five years. (21-23) 
Porcelain laminate veneers have undergone significant progression. Nowadays, Porcelain fired on refractory dies is called feldspathic porcelain, in which Porcelain materials are consists of finely ground ceramic powders that were mixed with distilled water or a special liquid. A "master" working cast is poured of die stone and by using a layering and firing process, the ceramic technician would construct the veneers. Advantages of feldspathic porcelain veneers may include their reasonable cost; the layering technique is compatible with both ceramist skills \& lab equipments. The porcelain powders \& investments used in feldspathic porcelain veneers are relatively inexpensive. The disadvantage of this type appeared in problems with fit and strength that many dentists complained. Porcelain laminate veneers fabricated with this technique must be handled gently during try-in to avoid fracture even after cementation. A good bond between veneer and enamel is very essential to reinforce the veneer restoration. (24-26)

\section{Heat pressed glass ceramic:-}

Finer porcelain crystals produce stronger materials. Properties improvement of laminate veneers depends on the crystals interaction and matrix glassy, as well as on the amount of porcelain crystals and their size. By adding certain types of fillers that are uniformly dispersed throughout the glass, increased strength in glassy ceramics is achieved. Zirconia, aluminum, leucite, magnesium, and lithium di-silicate are examples for these types of fillers. Such glassceramics were stronger with a higher melting point than non-crystalline glass and also had variable coefficients of thermal expansion. First, the glass-ceramic material called (Dicor) was introduced. It was made by using a lost-wax and centrifugal casting process. The translucency was the main disadvantage of the material because it necessitated the external application of all shading. A few years later, another reinforced glass-ceramic systems called (leucite) was introduced. The material is heated to a high temperature and pneumatically pressed and the resultant microstructure is similar to that of powder porcelains; however, less porous and a higher crystalline content is the main advantage of the final laminate porcelain veneer constructed from leucite system. Due to its favorable strength and shade, the manufacturer's instructions recommend its use for inlays, onlays, veneers anterior or posterior crowns and implant crowns (27-30).

\section{Chair-side computer aided design \ computer assessed manufacturing (CAD-CAM) system.:-}

Currently, computer-aided design/computer-assessed manufacturing (CAD/CAM) makes veneers construction easier. Because the ceramic blocks have a translucent quality that resembles the structure of enamel, CAD/CAM veneers have a natural appearance in addition to have a wide range of shades. Internal defects and voids of prefabricated ceramic blocks is usually not found subsequently quality of final restoration is consistent. $(31,32)$ The optical techniques of Moire fringe displacement was used in CEREC systems and the height \& depth of the preparation were measured by active triangulation technique presented in the device system. After preparation, an optical impression taken by operator to reveal the whole details of the preparation \& surrounding structures is transmitted and shown on a monitor, allowing the system to assist in designation of the final restoration. Within minutes, a micro-milling devise mills the ceramic block to gain a high-quality ceramic veneers. Only high coast and need for extra training for dentist and other auxiliaries may be the cause of some limitation of CADICAM in some populations (33-36).

\section{Indications and contraindications for laminate veneers:-}

Due to susceptibility of problems with long-term, Using of composite resin to treat discolored tooth or unfavorable tooth position\shape become limited. Disadvantages of composite resin with long-term include the ability for marginal fractures, excessive wear and surface discoloration. Ceramic veneers become the best substitute for treatment of esthetic problems with conservative tooth approach (3). Indications of Porcelain laminate veneers may include correction of minor malformations of anterior teeth with minimal removal of the remaining tooth structure, correction of crown length\& width, diastma closure, masking intrinsic discoloration of anterior teeth that is resistant to vital bleaching procedures like dental fluorosis and tetracycline staining, teeth need for incisal length augmentation, teeth with extensive enamel loss due to wear \& erosion and teeth suffering from generalized congenital malformations. On the other hand, Contraindications of veneers may include patient with sever parafunctional habits, bruxism, sever tooth mal-position, sever periodontal disease, teeth with small distance interocclusaly, anterior teeth with deep vertical overlap and any other situations that impair the proper placement of laminate veneers (3-5).

\section{Tooth preparation:-}

\section{Preparation of incisal edge:-}

Three preparation designs have been suggested regarding the incisal edge preparation of ceramic laminate veneers; the window or inter-enamel preparation, the incisal bevel $0.5-1 \mathrm{~mm}$ and the overlapped incisal edge $2-4 \mathrm{~mm}$ 
preparation. For the first technique of preparation; the window or inter-enamel preparation is commonly used for minimal teeth preparation that suffering from stains or discoloration with no need for crown length correction. In this technique, the main preparation is on the labial or facial tooth surface and the incisal portion just prepared from facial surface and no preparation at all done at both incisal edge and palatal surface. The disadvantages manifested as decreased retention and weakened incisal portion of ceramic laminate veneers. For the second preparation technique; the study of Castelnuovo et.al, revealed that the incisal bevel of $0.5-1 \mathrm{~mm}$ will result in nearly a butt joint and the palatal reduction of incisal edge will make a chamfer finishing line. Both will lead to more strength of veneer at this area in addition to easy preparation technique. They also concluded that to decrease the risk of broken thin shell of non-supported veneers ledges, the incisal bevel $0.5-1 \mathrm{~mm}$ will strongly achieving that purpose especially in the case of multiple numbers of ceramic laminate veneers (37).

Regarding the third preparation technique i.e. the edge-lapped or the overlapped incisal edge 2-4 $\mathrm{mm}$ preparation; the study of Akoğlu and Gemalmaz (38) have been assessed the failure mode and the load of fracture of ceramic laminate veneers when the preparation are done and finished at either enamel or dentin. They revealed that the lower fracture load was achieved when $4 \mathrm{~mm}$ incisal reduction entirely done on dentin surface than those of only $2 \mathrm{~mm}$ dentin reduction. They also concluded that the fracture resistance was nearly similar with no statistical significant difference for both veneers of less than $2 \mathrm{~mm}$ preparation at incisal edge area and the intact teeth with no incisal edge preparation (the window type). Dentist should be able to choose the proper preparation technique either incisal edge beveling $(0.5-1 \mathrm{~mm})$ or complete over-lapped technique $(2-4 \mathrm{~mm})$ according situation of the case to achieve long lasting veneers. Better results were obtained when palatal surface and incisal edge preparation were guided by silicone index than with depth gauge bur (39).

\section{Preparation of labial surface:-}

Because this surface resembles the most esthetic portion of ceramic laminate veneers, obtaining the accurate preparation depth can be achieved via several methods. Use of depth cutter burs are very useful to make slandered grooves or cuts that control preparation depth. The recommended depth for minimal invasive approach is $0.5 \mathrm{~mm}$. The silicon putty index after wax up may also be helpful but less than its usefulness in the area of incisal edge preparation. Some expertise, highly experienced and well trained operators using a "free-hand" technique with no depth preparation guidance depending on their tactile sensation. Free-hand technique is not recommended for beginners and newly dentist to avoid the risk of overcutting or unequal reduction levels of labial tooth surface. Nattress et al. revealed that dentin exposure and variable preparation depth can be resulted from using free-hand technique (40).

In the study of Ferrari et al. (41) they evaluated and measured the labial surface of one hundred fourteen extracted human teeth at three locations, the incisal, the middle and the gingival thirds. Examined teeth were anteriors and premolars. They tried to measure the labial enamel thickness at these sites. They revealed that there is a problem to be solved. Enamel of labial surface should be reduced 0.5 in all mentioned thirds in order to get a proper thickness for ceramic laminate veneer that is enough to mask tooth stains or discoloration. But they found that thickness of enamel differed in the three third, while thickness was $1-1.5 \mathrm{~mm}$ at incsal third, $0.5-0.7 \mathrm{~mm}$ at middle third, it was $0.3-0.4 \mathrm{~mm}$ at gingival third. This would lead to either removal of entire enamel thickness plus dentin exposure at gingival third or an over-contoured veneers could be the final resulted with minimal invasive approach. The dilemma was the more conservative reduction at gingival third will lead to bulky veneers with subsequent gingival problems. On the other hand, the more extensive exposure of dentin would resulted in an over-reduction (42-44). As mentioned before, the risks with free-hand technique include appearance of areas of both unnecessarily extensive reduction and inadequate under-preparation within the same tooth surface. Using of depth gauge bur or silicon putty index silicon is highly recommended for newly dentists when teeth to be prepared for ceramic laminate veneers. Only in case of severely intrinsic teeth discoloration like deep grayish blue tetracycline stains, using of a nonuniform preparation e.g. free-hand technique may be preferable to prevent stain display under the thin ceramic veneers in order to increase the esthetic outcome success. The shade and quality of used resin cement and the thick bulky veneer increasing the ability of stain masking (45). Introduction of newly ceramics fabrication devices, and increase the numbers of highly skilled, well trained ceramic technicians, increasing the ability to adopt the minimally invasive approach of tooth preparation for porcelain laminate veneers.

Wells revealed that the no-preparation technique can be strongly recommended in some situations without interfering with gingival tissue heath (46). Tooth with lingual retraction between normal aligned teeth is an example for this recommendation. Fabrication of small thickness veneers means that operator followed the approach of 
minimally invasive tooth preparation. This can be recommended in case of teeth with non-sever intrinsic discoloration that can be easily esthetically improved by minor teeth preparation and masked by smaller thickness veneers $(39,47,48)$.

In general, it is recommended to use the minimally invasive technique with teeth need for minimal correction at the incisal edge, in diastma closure, in modifications of small fractures at incisal angle of anterior teeth and when indirectly restored the pig-shaped lateral incisors. Preservation of incisal edge intact without preparation may lead to just facial window type of preparation and no need for incisal edge-overlapped type. Although edge-lapped preparation type gives more retention and resistance for porcelain laminate veneers, it is not recommended if there is no need for correction of tooth crown length.

Some modification of reduction depth with minimally invasive approach for porcelain laminate veneers taken place. Cervical third reduction became $(0.1 \mathrm{~mm})$, the middle third reduction became $(0.2-0.5 \mathrm{~mm})$ and the incisal edge reduction became $(0.7-1.0 \mathrm{~mm})$. (48)

\section{Preparation of interproximal surface:-}

There is no restricted roles regarding the interproximal tooth preparation for ceramic veneers. Some authors recommended no-preparation especially with window type when a minor tooth discoloration confined to facial surface with no interproximal extensions. Others advised a conservative interproximal preparation with no contact area opening. This recommended if discoloration extended at proximal area. In case of diastma closure, slight opening of interproximal contacts is recommended. In some situation when preparing a multiple teeth with tight contact, a "slice preparation" or breakage of the contact may be advisable in order to free-way the contacts and enhance contour adjustment $(13,49)$.

\section{Cervical margin preparation:-}

Cervical margins of porcelain laminate veneers is one of the critical areas from esthetic and biological points of view. Finishing line may be at one of three locations; supra-gingival, at gingival or sub-gingival.

Supra-gingival finishing line is more hygienic and biological for gingival tissues but less esthetic. Chamfer finish line is more accepted and will be more beneficiary for ceramics technician to determine where to build and construct the porcelain laminate veneers $(46,50)$ Sub-gingival finishing line is more esthetic but less biocompatible for gingival tissues. This type can be used efficiently in case of severely discolored teeth like in case of tetracycline stains to mask the undesirable discoloration at cervical margins. Cervical region are area of challenge for luting cement as fluids secreted from gingival crevice impair a good seal between the fitting surface of laminate veneer and the tooth structure. Most studies concluded that if the tooth preparation was more conservative and confined to enamel, the bond strength between recent resin cements and enamel will be better than with dentin $(3,12,51)$.

\section{Conclusion:-}

Ceramic laminate veneers offer the clinicians various solutions for many situations that need esthetic dental improvement. Minimal invasive approach can be achieved through less tooth preparation and thin shell veneers or lumineers. Operator's knowledge and skill play an important role in success and failure of ceramic laminate veneers.

\section{References:-}

1. McLaren EA, Whiteman YY. Ceramics: rationale for material selection. Compend Contin Educ Dent. 2010; 31(9):666-668.

2. McLaren EA, LeSage B. Feldspathic veneers: what are their indications? Compend Contin Educ Dent. 2011; 32(3):44-49.

3. Radz GM. Minimum thickness anterior porcelain restorations. Dent Clin North Am. 2011; 55(2):353-370.

4. Belser UC, Magne P, Magne M. Ceramic laminate veneers: continuous evolution of indications. J Esthet Dent. 1997; 9(4):197-207.

5. Strassler HE. Minimally invasive porcelain veneers: indications for a conservative esthetic dentistry treatment modality. Gen Dent. 2007; 55(7):686-694.

6. Peumans B, Van Meerbeek B, Lambrechts P, Vanherle G. Porcelain veneers: a review of the literature. J Dent. $2000 ; 28: 163-177$. 
7. MEDLINE® [database on the Internet]. Bethesda, MD: National Library of Medicine; nd. Available from: http://www.ncbi.nlm.nih. gov/pubmed/. Accessed January 9, 2011.

8. PubMed.gov [database on the Internet]. Bethesda, MD: National Center for Biotechnology Information, US Library of Medicine; nd. Available from: http://www.ncbi.nlm.nih.gov/pubmed/. Accessed January 9, 2011.

9. Donovan T. Factors essential for successful all-ceramic restorations. J Am Dent Assoc. 2008; Suppl 139:14S$18 \mathrm{~S}$.

10. Soares CJ, Soares PV, Pereira JC, Fonseca RB. Surface treatment protocols in the cementation process of ceramic and laboratory-composite restorations: a literature review. J Esthet Rest Dent. 2005; 17: 224-235.

11. Giordano R, McLaren EA. Ceramics overview: classification by microstructure and processing methods. Compend Contin Educ Dent. 2010; 31(9):682-684.

12. Peumans M, De Munck J, Fieuws S, Lambrecht P, Vanherle G, Van Meerbeek V. Prospective ten-year clinical trial of porcelain veneers. J Adhes Dent. 2004; 6(1):65-76.

13. Walls AW. The use of adhesively retained all-porcelain veneers during the management of fractured and worn anterior teeth. Part II: clinical results after 5-years follow-up. Br Dent J. 1995; 178:337-339.

14. Della Bona A, Kelly JR. The clinical success of all-ceramic restorations. J Am Dent Assoc. 2008; Suppl 139:8S-13S.

15. Davidowitz G, Kotick PG. The use of CAD/CAM in Dentistry. Dent Clin North Am. 2011;55(3):559-570.

16. Seydler B, Schimitter M. Esthetic restoration of maxillary incisors using CAD/CAM chairside technology - a case report. Quintessence Int. 2011;42:533-537.

17. Wittneben JG, Wright RF, Weber HP, Gallucci GO. A systematic review of the clinical performance of CAD/CAN single-tooth restorations. Int J Prosthodont. 2009;22:446-471.

18. Wiedhahn K, Kerschbaum T, Fasbinder DF. Clinical long-term results with 617 Cerec veneers: a nine-year report. Int J Comput Dent. 2005;8:233-246.

19. Culp L, McLaren EA. Lithium disilicate: the restorative material of multiple options. Compend Contin Educ Dent. 2010;31(9):716-720, 722, 724-725

20. Narasimha Raghavan (2012). Ceramics in Dentistry, Sintering of Ceramics - New Emerging Techniques, Dr. Arunachalam Lakshmanan (Ed.), InTech, DOI: 10.5772/39090. Available from: https://www.intechopen.com/books/sintering-of-ceramics-new-emerging-techniques/ceramics-in-dentistry

21. Layton D, Walton T. An up to 16-year prospective study of 304 porcelain veneers. Int J Prosthodont. 2007;20(4):389-396.

22. Fradeani M, Redemagni M, Corrado M. Porcelain laminate veneers: 6- to 12-year clinical evaluation - a retrospective study. Int J Periodontics Restor Dent. 2005;25(1):9-17.

23. Della Bona A. Bonding to Ceramics: Scientific Evidences for Clinical Dentistry. São Paulo: Artes Médicas; 2009.

24. McLaren EA, LeSage B. Feldspathic veneers: what are their indications? Compend Contin Educ Dent. 2011;32(3):44-49.

25. McLaren EA, Whiteman YY. Ceramics: rationale for material selection. Compend Contin Educ Dent. 2010;31(9):666-668.

26. Calamia JR, Calamia CS. Porcelain laminate veneers: reasons for 25 years of success. Dent Clin N Am. 2007;51:399-417.

27. Guess PC, Schultheis S, Bonfante EA, Coelho PG, Ferencz J, Silva NRFA. All-ceramic systems: laboratory and clinical performance. Dent Clin North Am. 2011;55(2):333-352.

28. K.A. Malament, S.S. Socransky, "Survival of Dicor glass-ceramic dental restorations over 16 years. Part III: effect of luting agent and tooth or tooth-substitute core structure". The Journal of Prosthetic Dentistry.2001;86:511-519.

29. E.A. Tsitrou, M. Helvatjoglu-Antoniades, R.van Noort, "A preliminary evaluation of the structural integrity and fracture mode of minimally prepared resin bonded CAD/CAM crowns", J Dent. 2010;38(1):16-22.

30. I. Denry, "How and when does fabrication damage adversely affect the clinical performance of ceramic restorations? " Dental Materials. 2013;29:85-96.

31. Davidowitz G, Kotick PG. The use of CAD/CAM in Dentistry. Dent Clin North Am. 2011;55(3):559-570.

32. Seydler B, Schimitter M. Esthetic restoration of maxillary incisors using CAD/CAM chairside technology - a case report. Quintessence Int. 2011;42:533-537.

33. Berg NG, Derand T. A 5-year evaluation of ceramic inlays (CEREC). Swed Dent J. 1997;21(4):121-127.

34. Mörmann WH. The evaluation of the CEREC system. J Am Dent Assoc 2006;137 (suppl):7S-13S.

35. Duret F, Blonin J, Duret B. CAD/CAM in dentistry, JADA 1998; 117:715-720. 
36. Trifković B, Todorović A, Lazić V, Dragnjac M, Mirković N, Jokić B. Accuracy of optical scanning methods of the Cerec 3D system in the process of making ceramic inlays. Vojnosanit pregl 2010; 67(10): 795-876.

37. Castelnuovo J, Tjan AHL, Phillips K, Nicholls JI, Kois JC. Fracture load and mode of failure of ceramic veneers with different preparations. J Prosthet Dent. 2000;83(2):171-180.

38. 38. Akoğlu B, Gemalmaz D. Fracture resistance of ceramic veneers with different preparation designs. J Prosthodont. 2011;20(5):380-384.

39. 39. Brunton PA, Aminian A, Wilson NH. Tooth preparation techniques for porcelain laminate veneers. Br Dent J. 2000;189(5):260-262.

40. Nattress BR, Youngson CC, Patterson CJ, Martin DM, Ralph JP. An in vitro assessment of tooth preparation for porcelain veneer restorations. J Dent. 1995;23(3):165-170.

41. Ferrari M, Patroni S, Balleri P. Measurement of enamel thickness in relation to reduction for etched laminate veneers. Int J Periodontics Restorative Dent. 1992;12(5):407-413.

42. Parmeijer CH. Porcelain laminate veneers. J Calif Dent Assoc. 1991; 19(4):59-62.

43. Weinberg LA. Tooth preparation for porcelain laminates. N Y State Dent J. 1989;55(5):25-28.

44. Clyde JS, Gilmour A. Porcelain veneers: a preliminary review. Br Dent J. 1988;164(1):9-14.

45. Chen JH, Shi CX, Wang M, Zhao SJ, Wang H. Clinical evaluation of 546 tetracycline-stained teeth treated with porcelain laminate veneers. J Dent. 2005;33(1):3-8.

46. Wells DJ. "No-prep" veneers. Inside Dent. 2010;6(8):56-60.

42. 47. Magne P, Belser UC. Bonded Porcelain Restorations in the Anterior Dentition-a Biomimetic Approach. Chicago: Quintessence Publishing Co; 2002.

43. 48. Pini NP, Aguiar FH, Lima DA, Lovadino JR, Terada RS, Pascotto RC. Advances in dental veneers: materials, applications, and techniques. Clin Cosmet Investig Dent. 2012;4:9-16.

49. Strassler HE, Weiner S. Seven to ten-year clinical evaluation of porcelain laminate veneers. J Dent Res. 1995;74:176.

50. Dumfahrt H. Porcelain laminate veneers. A retrospective evaluation after 1 to 10 years of service: Part I Clinical procedure. Int J Prosthodont. 1999;12(6):505-513.

51. Aristidis GA, Dimitra B. Five-year clinical performance of porcelain laminate veneers. Quintessence Int. 2002;33(3):185-189. 